\title{
Stroke Associated with Covid-19 at the Yaoundé General Hospital, Cameroon: Series of 10 Cases
}

\section{Paul-Cédric Mbonda ${ }^{*}$, Victor Sini ${ }^{2}$, Jose Kamgang ${ }^{3}$, Hadja Cherif ${ }^{4}$, Alain Menanga ${ }^{1}$, Victor Eyenga1, Callixte Kuate ${ }^{1}$, Vincent de Paul Djientcheu ${ }^{1}$}

${ }^{1}$ Faculty of Medicine and Biomedical Sciences, University of Yaoundé 1, Yaoundé, Cameroon

${ }^{2}$ Neurology Department, Yaoundé General Hospital, Yaoundé, Cameroon

${ }^{3}$ Emergencies Department, Yaoundé General Hospital, Yaoundé, Cameroon

${ }^{4}$ Infectious diseases Department, Yaoundé General Hospital, Yaoundé, Cameroon

Email: ^mbondapaul@gmail.com

How to cite this paper: Mbonda, P.-C., Sini, V., Kamgang, J., Cherif, H., Menanga, A., Eyenga, V., Kuate, C. and de Paul Djientcheu, V. (2021) Stroke Associated with Covid-19 at the Yaoundé General Hospital, Cameroon: Series of 10 Cases. World Journal of Neuroscience, 11, 221-230. https://doi.org/10.4236/wjns.2021.113016

Received: June 3, 2021

Accepted: August 7, 2021

Published: August 10, 2021

Copyright $\odot 2021$ by author(s) and Scientific Research Publishing Inc. This work is licensed under the Creative Commons Attribution International License (CC BY 4.0).

http://creativecommons.org/licenses/by/4.0/ (c) (i) Open Access

\begin{abstract}
Background: The Covid-19 pandemic, which is an infection due to the SARS Cov-2 virus, mainly causes severe damage to the respiratory system, but several studies have reported neurological damage with different manifestations including headaches, seizures, encephalopathies, and stroke. We report a series of 10 patients infected with Covid-19 who had an ischemic stroke at the Yaoundé General Hospital, Cameroon. Patients and Methods: We carried out a prospective study for 12 months between April 2020 and March 2021 by collecting data from patients admitted for Covid-19 at the Yaoundé general hospital. Were included all patients with a diagnosis of stroke confirmed by brain imaging (CT/MRI) following a focal neurological deficit of sudden onset and whose test (nasopharyngeal swab confirmed by PCR) for Covid-19 was positive. Patients diagnosed with a stroke more than 2 weeks (14 days) after the positive Covid-19 PCR test were excluded. Results: The prevalence of ischemic stroke in this hospital-based series was $1.46 \%$. These were six men and four women. The mean NIHSS score was 13.57. The average age of our patients was 58 years. Brain imaging was performed in each patient revealing hypodense lesion in a large arterial territory in 8 of them, for two patients we found multilacunar infarcts. All patients had negative HIV serology and D-dimers greater than $500 \mu \mathrm{g} / \mathrm{L}$. Conclusion: This work on strokes in Covid-19 infected patients shows that it is a fairly frequent neurological complication, which can occur even in young subjects without known risk factors, the symptoms of viral infection are not systematically present before the onset of stroke.
\end{abstract}




\section{Keywords}

Covid-19, Stroke, Ischemia

\section{Introduction}

The Covid-19 pandemic, which is an infection due to the SARS Cov-2 virus, has been raging across the world since the end of 2019, causing many deaths in the populations, as well as social, psychological, and economic impact almost never seen in the world [1]. The African continent, despite its relatively young population, is not spared and is currently receiving its first doses of vaccines. Cameroon is one of the most affected countries in sub-Saharan Africa and the largest numbers of cases are recorded in Yaoundé, the political capital [2]. Covid-19 infection mainly causes severe damage to the respiratory system, but several studies have reported neurological damage with different manifestations including headache, seizures, encephalopathies, and ischemic stroke, hence the term "NeuroCovid" [3].

This term, described by several authors, refers to the neurological manifestations associated with Covid-19 infection, which affects the central nervous system with manifestations more described such as headache, encephalopathy (cognitive disorders, confusion, and disorientation), ischemic and hemorrhagic strokes, meningoencephalitis, cerebral venous thrombosis, epilepsy, acute disseminated encephalomyelitis. The peripheral nervous system is also concerned, several cases of anosmia, ageusia, Bell's facial palsy (and facial diplegia), Guillain-Barré syndrome, and variants including Miller Fisher syndrome, myopathy, isolated oculomotor neuropathy, have been described [4]. In severe presentations of NeuroCovid, some patients exhibit acute necrotizing encephalopathy, Bickerstaff's encephalitis, generalized myoclonus, acute transverse myelitis, limbic encephalitis, akinetic mutism, and even coma [5]. However, we must note that sometimes the neurological manifestations can precede the typical signs like fever and cough, and later on classical manifestations develop in these patients.

These neurological complications may result from a variety of mechanisms, including virus-induced hyperinflammatory and hypercoagulable states (Characteristic cytokine storm incites severe metabolic changes and multiple organ failure), direct virus infection of the central nervous system (CNS), and postinfectious immune mediated processes. Viral neuroinvasion may be achieved by several routes, including transsynaptic transfer across infected neurons, entry via the olfactory nerve, infection of vascular endothelium, or leukocyte migration across the blood-brain barrier [6]. More neuropathological studies in COVID-19 patients reveled different patterns of CNS damage, particularly ischemic and hemorrhagic changes, and inflammatory injuries. An autopsy study on Covid-19 patients demonstrated the presence of the virus in the brain of some patients 
with neurocovid [5].

In the literature, we don't find many studies in Sub-Saharan Africa, studies are scarce describing neurological complications of Covid-19, especially strokes. We report a series of 10 patients infected with Covid-19 who had an ischemic stroke at the Yaoundé General Hospital in Cameroon.

\section{Patients and Methods}

We carried out a prospective study for 12 months between April 2020 and March 2021 by collecting data from patients admitted for Covid-19 at the Yaoundé general hospital.

Yaoundé General Hospital is a 1st category referral hospital in Cameroon, with a capacity of more than 200 beds, hospitalizing symptomatic patients with Covid-19 for a year. They were followed-up by consultant infectious diseases specialists and emergency consultants. A consultant neurologist was called for any patient presenting with neurological signs (neurocovid).

Were included all patients with a diagnosis of stroke confirmed by brain imaging (CT/MRI) following a focal neurological deficit of sudden onset and whose test (nasopharyngeal swab confirmed by PCR) for Covid-19 was positive. Patients diagnosed with a stroke more than 2 weeks (14 days) after the positive Covid-19 PCR test were excluded.

The following examinations were carried out in all our patients: Full Blood Count, blood urea and creatinine, fasting blood glucose, blood electrolytes, HIV serology, D-dimers, CRP, cardiac ultrasound, Electrocardiogram, Echodoppler of the supra-aortic arteries. All socio-demographic, clinical and therapeutic data were collected, and each patient was monitored to date.

Data were presented as frequency and percentages for categorical variables and median with interquartile range for continuous variables, unless otherwise stated. Comparisons between patients were made using Fisher's exact test for categorical variables and Mann-Whitney $U$ test for continuous variables. Statistical significance was defined as $\mathrm{p} \leq 0.05$. Statistical analyses were performed with STATA (version 16, StataCorp, College Station, TX, USA).

Institutional review board approval was obtained for this work.

\section{Results}

From April 2020 to March 2021 we identified 684 cases of positive Covid-19 patients. Of which 10 presented with ischemic stroke. The prevalence of ischemic stroke in this hospital-based series was $1.46 \%$. These stroke patients were six men and four women. The average age of our patients was 58 years with extremes of 36 and 81 years. Clinical and paraclinical characteristics of patients are summarized in Table 1. Among the comorbidities, type 2 diabetes (50\%) and high blood pressure (30\%) were the most common. For 7 patients (70\%) the infection with Covid-19 was severe and associated with respiratory distress according to the WHO classification. 
Table 1. Clinical and paraclinical characteristics of patients.

\begin{tabular}{|c|c|c|c|c|c|c|c|c|}
\hline Items & Age & Sexe & Comorbidities & $\begin{array}{l}\text { NIHSS } \\
\text { Score }\end{array}$ & $\begin{array}{l}\text { Covid-19 } \\
\text { Symptoms }\end{array}$ & CT scan/IRM & Vascular Territory & Comments \\
\hline 1 & 49 & M & Diabetes & 17 & $\begin{array}{l}\text { Respiratory } \\
\text { distress, fever }\end{array}$ & CT Scan & Middle cerebral artery & $\begin{array}{l}\text { Sequelae of hemiplegia and } \\
\text { post-stroke depression }\end{array}$ \\
\hline 2 & 63 & $\mathrm{~F}$ & $\begin{array}{l}\text { High blood pressure, } \\
\text { Heart failure }\end{array}$ & 14 & $\begin{array}{l}\text { Respiratory } \\
\text { distress, }\end{array}$ & CT Scan & $\begin{array}{l}\text { Middle and anterior } \\
\text { cerebral arteries }\end{array}$ & Good outcome \\
\hline 3 & 81 & $\mathrm{~F}$ & $\begin{array}{l}\text { High blood pressure, } \\
\text { Heart failure }\end{array}$ & 15 & $\begin{array}{l}\text { Respiratory } \\
\text { distress, }\end{array}$ & CT Scan & Middle cerebral artery & Sequelae of hemiplegia \\
\hline 4 & 42 & M & No comorbidity & 6 & Headaches & CT Scan & Lacunar infarcts & Good outcome \\
\hline 5 & 36 & M & No comorbidity & 8 & Headaches & CT Scan & Middle cerebral artery & Sequelae of hemiplegia \\
\hline 6 & 57 & M & $\begin{array}{l}\text { Diabetes, High blood } \\
\text { pressure }\end{array}$ & 17 & Fever & CT Scan & Middle cerebral artery & $\begin{array}{l}\text { Sequelae of hemiplegia, aphasia } \\
\text { and post-stroke depression }\end{array}$ \\
\hline 7 & 55 & M & No comorbidity & 18 & Fever & CT Scan & Middle cerebral artery & Death \\
\hline 8 & 66 & M & Diabetes & 12 & $\begin{array}{l}\text { Respiratory } \\
\text { distress, fever }\end{array}$ & MRI & Lacunar infarcts & Death \\
\hline 9 & 68 & $\mathrm{~F}$ & Diabetes & 14 & Fever & CT Scan & Middle cerebral artery & $\begin{array}{l}\text { Sequelae of hemiplegia and } \\
\text { post-stroke depression }\end{array}$ \\
\hline 10 & 62 & $\mathrm{~F}$ & High blood pressure & 12 & $\begin{array}{l}\text { Respiratory } \\
\text { distress, }\end{array}$ & CT Scan & Middle cerebral artery & Sequelae of hemiplegia \\
\hline
\end{tabular}

Symptoms and signs of patients were predominantly neurological (see Table 2 ), with motor deficit found in all patients, followed by headaches, fever and respiratory distress in $70 \%$ of patients $(\mathrm{p}<0.001)$.

The median time to consultation for motor deficit was 14 hours with extremes ranging from 2 to 36 hours.

Four patients (40\%) had total right hemiplegia with aphasia, 5 patients (50\%) had severe left hemiplegia, and only one patient had a discrete motor deficit (left hemiparesis and fast recovery). The mean NIHSS score was 13.57 with extremes of 6 to 18 .

Among patients with signs of Covid-19 before the onset of stroke, the motor deficit occurred on average 10 days after the onset of symptoms $(\mathrm{p}<0.001)$. Seizures were found in 2 patients $(20 \%)$ at the acute phase of stroke, four patients (40\%) presented with confusional state during their hospitalization.

A chest CT scan was performed in $50 \%$ of patients, revealing pulmonary lesions typical of SARS-Cov-2 (Figure 1). Brain imaging was performed in each patient revealing hypodense lesion in a large arterial territory (Figure 2) in 8 of them (right middle cerebral artery for $50 \%$ of patients and left middle cerebral artery for $30 \%$ ), for 2 patients we found multilacunar infarcts.

Only one patient underwent a lumbar puncture and analysis of the cerebrospinal fluid was normal.

All the patients had negative HIV serology; CRP was greater than $6 \mathrm{mg} / \mathrm{l}$ in all patients and D-dimers greater than $500 \mu \mathrm{g} / \mathrm{l}$. 
Table 2. Symptoms of patients.

\begin{tabular}{ccc}
\hline Symptoms & Number & Percentage (\%) \\
\hline Motor deficit & 10 & 100 \\
Headaches & 8 & 80 \\
Fever & 7 & 70 \\
Dyspnea & 7 & 70 \\
Confusion & 3 & 30 \\
Focal seizures & 2 & 20 \\
\hline
\end{tabular}

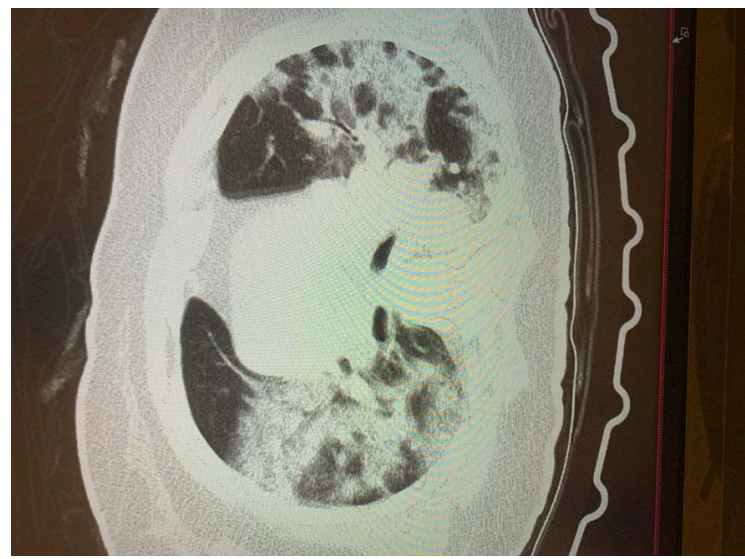

Figure 1. Chest CT scan SARS COV 2 lesions with $70 \%$ involvement.

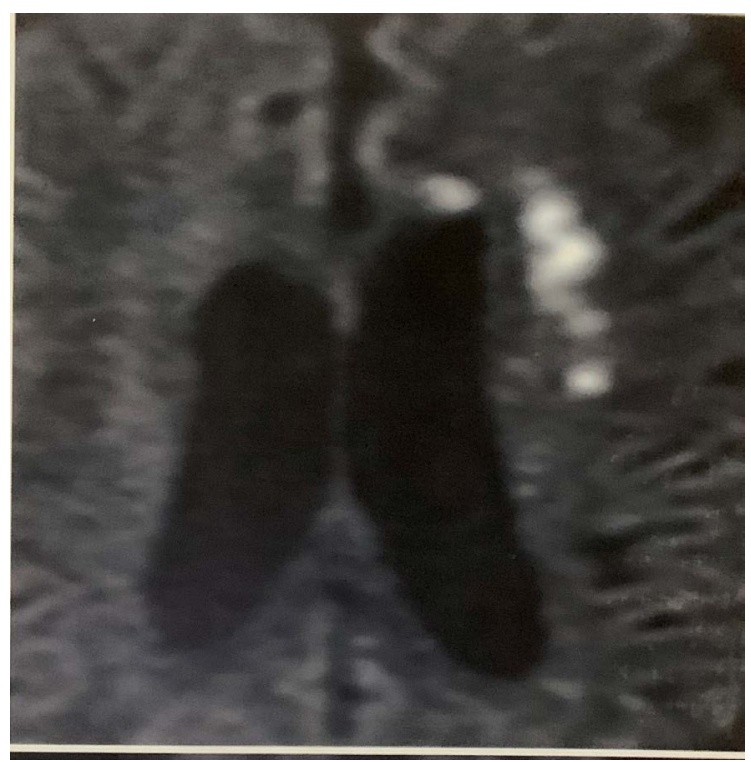

Figure 2. Brain MRI diffusion sequence revealing multi lacunar infarcts.

Regarding the treatment, depending on the clinical condition and the comorbidities, the patients received low aspirin (100 mg daily) as well as Enoxaparin at a preventive dose or anticoagulant medication (rivaroxaban at $15 \mathrm{mg} /$ daily), pa- 
racetamol at 1 gram 3 times/day. Antibiotic therapy based on azithromycin 500 $\mathrm{mg}$ for 3 days, and amoxicillin clavulanic acid $1 \mathrm{~g} 3$ times a day for 10 days, vitamin $\mathrm{C}$ and zinc for 10 days. With management of high blood pressure and diabetes for patients with these co-morbidities who were also given statins.

All patients whose oxygen saturation was less than $94 \%$ were put on oxygen therapy.

At the end of follow-up two patients (20\%) died, four patients had hemiplegia including one with Broca's aphasia despite speech therapy and three also suffer from post-stroke depression. The average duration of hospitalization was 31 days with extremes ranging from 14 to 45 days.

\section{Discussion}

The neurological complications of Covid-19 are well known and described by several authors, the central nervous system being more affected and headaches were most often found, stroke is one of these complications but are not very frequent [7] [8]. We found a prevalence of $1.46 \%$ of stroke in Covid-19 patients in our series, in the various reviews described by Tan et al. [9] on more than 5000 patients and Nannoni et al. [10] on more than 100,000 patients, the prevalence of stroke in patients with Covid-19 was $1.2 \%$ and $1.4 \%$, respectively. Stroke is not very common in Covid-19 infection but its prevalence might be underestimated given the rapid deaths, and access to imaging which is not always possible for all patients.

The average age in our series was 58 years, these results are relatively lower than those (64 years) found by Tan [9] as well as Morassi in a series of cases in Italy [11] where the average age was 69 years old. This can be explained by a longer life expectancy in these countries compared to ours. The predominance of the male sex is also found in several series of similar cases, reported in Paris [12] and Guinea-Conakry [13] in Africa, the male sex being a cardiovascular risk factor and this could explain the fact of finding more men in many studies.

Covid-19 infection manifests with various symptoms, but patients may remain asymptomatic [14] before the onset of stroke. Among our symptomatic patients, complaints such as headache, asthenia, and cough occurred on average 10 days before the motor deficit.

Escalard et al. [14] found an average of 6 days between symptoms and the onset of stroke, Covid-19 causes inflammatory states, hypercoagubility and endothelial dysfunction which would be one of the damage mechanisms of the central nervous system [15]. This could explain these delays of a few days before the onset of stroke but also the greater frequency of ischemia according to several series reported. Nannoni et al. [10] in a review of the literature of 2277 manuscript on strokes associated with Covid- 19 found $87 \%$ of ischemia.

Co-morbidities were found in $70 \%$ of our patients which could explain the occurrence of stroke, but for our two patients who were young without vascular risk factors and in whom we could not find an etiology to their ischemic stroke despite the examinations requested: Ultrasonography of the supra-aortic arte- 
ries, Electrocardiogram, Cardiac ultrasound, HIV serology, S and C proteins, antithrombin III. For these patients, Covid 19 infection could be the cause of their ischemic stroke.

Confusional states and impaired vigilance are associated with a high mortality rate in Covid-19 infection [16], two-thirds of our patients with confusional states died in our series. The NIHSS score is higher in strokes linked to Covid-19 infection than without [10]; this can be explained by respiratory involvement which is sometimes severe but also involvement of the large vessels more frequent [17] particularly when the patient has several comorbidities. Two-thirds of our patients had an NIHSS score greater than 15, and their course was marked by severe sensory-motor sequelae, and death.

Neuroimaging studies of positive Covid-19 patients reveal more involvement of the great vessels [18], Escalar describes more severe ischemia and more vessels affected in a case-control study [14]. This could be explained by the risk of embolization which increases with Covid-19 infection; $80 \%$ of our patients had large vessel involvement with total hemiplegia, only two patients had cerebral deficiencies including a slight motor deficit.

The cerebrospinal fluid analysis was performed in one of our patients and was normal ( 2 cells, $0.38 \mathrm{~g} / \mathrm{l}$ of protein and $0.6 \mathrm{~g} / \mathrm{l}$ of glucose). Several authors describe markers of inflammation in the cerebrospinal fluid of Covid-19 patients [19], and some studies reveal the presence of viral particles in the cerebrospinal fluid during PCR [20], however these results may also be normal, the presence of SARS-COV2 in cerebrospinal fluid could be related to the severity of the systemic involvement, and the level of tropism of the virus in the nervous system [21].

For the management of our patients, we used our national protocol, all of them received antibiotics (azithromycin, amoxicillin-clavulanic acid or ceftriaxone), anticoagulants (enoxaparin combined with aspirin or rivaroxaban alone), oxygen was administered as needed, corticosteroid therapy was not systematic, hydroxychloroquine was not administered due to cardiac side effects. We found $20 \%$ of deaths in our series, these patients had severe lung involvement and Covid-19 infection was probably the main cause. The death rate varies from $25 \%$ - 85\% according to the different series of similar cases reported [6] [7] [8] [9], however the death rate from Covid-19 infection is $1.5 \%$ in Cameroon [22] therefore relatively low, further studies will be needed to better understand and explain these results.

Our study contains several limitations. First, the actual number of Covid-19 patients with stroke was probably underestimated, patients with severe impairment of consciousness or severe respiratory distress were unable to perform brain imaging. Also for some patients in whom the diagnosis of stroke was suspected, brain imaging was not performed due to financial constraints because health insurance is not available to the vast majority. Secondly, the Covid-19 pandemic causes real stress and some patients are afraid to come in a hospital environment, which skews the real number of infected patients but also several 
patients suffering from stroke, even minor ones, may not come for treatment in a hospital environment. Our sample size is small for work carried out over one year, which reveals that we must improve our communication with the populations, in order to carry out more screenings and to limit contamination but also to prevent and treat the complications of Covid-19 infection like stroke.

\section{Conclusion}

The Covid-19 pandemic is a global reality with multiple consequences, several systems are involved, and including the central nervous system and ischemic stroke is a well-described complication. This work on strokes in Covid-19 patients shows that it is a fairly frequent neurological complication, which can occur even in young subjects without known risk factors, the symptoms of viral infection are not systematically present before the onset of stroke. More studies should be done to better understand the mechanism, and to follow the evolution of brain damage on imaging.

\section{Acknowledgements}

To the health personnel of the Yaoundé General Hospital for all their efforts and sacrifices in fighting this pandemic.

\section{Ethics Approval}

This work was approved by the Regional Ethics Committee and carried out in accordance with the Declaration of Helsinki of 1964.

\section{Informed Consent}

Obtained with patient consent.

\section{Authors' Contribution}

PCM, JK, HC and VS examined the patient in hospital; PCM did all his follow-up and wrote the first draft of this manuscript. PCM, VS and VD revised subsequent versions and approved the final article.

\section{Conflicts of Interest}

Authors have no financial, political, personal, religious, ideological, academic, intellectual, commercial or any other conflicts of interest to declare in relation to this manuscript.

\section{References}

[1] Nicola, M., Alsafi, Z., Sohrabi, C., Kerwan, A., Al-Jabir, A., Iosifidis, C., Agha, M. and Agha, R. (2020) The Socio-Economic Implications of the Coronavirus Pandemic (COVID-19): A Review. International Journal of Surgery, 78, 185-193. https://doi.org/10.1016/j.ijsu.2020.04.018

[2] Mbopi-Keou, F.-X., Pondi, J.-E. and Sosso, M.A. (2020) COVID-19 in Cameroon: A 
Crucial Equation to Resolve. The Lancet Infectious Diseases, 20, 1367-1368. https://doi.org/10.1016/S1473-3099(20)30373-X

[3] Ellul, M.A., Benjamin, L., Singh, B., Lant, S., Michael, B.D., Easton, A., et al. (2020) Neurological Associations of COVID-19. The Lancet Neurology, 19, 767-783. https://doi.org/10.1016/S1474-4422(20)30221-0

[4] Payus, A.O., Liew Sat Lin, C., Mohd Noh, M., Jeffree, M.S. and Ali, R.A. (2020) SARS-CoV-2 Infection of the Nervous System: A Review of the Literature on Neurological Involvement in Novel Coronavirus Disease-(COVID-19). Bosnian Journal of Basic Medical Sciences, 20, 283-292. https://doi.org/10.17305/bjbms.2020.4860

[5] Maury, A., Lyoubi, A., Peiffer-Smadja, N., de Broucker, T. and Meppiel, E. (2021) Neurological Manifestations Associated with SARS-CoV-2 and Other Coronaviruses: A Narrative Review for Clinicians. Revue Neurologique, 177, 51-64. https://doi.org/10.1016/j.neurol.2020.10.001

[6] Hess, D.C., Eldahshan, W. and Rutkowski, E. (2020) COVID-19-Related Stroke. Translational Stroke Research, 11, 322-325. https://doi.org/10.1007/s12975-020-00818-9

[7] Divani, A.A., Andalib, S., Biller, J., Napoli, M.D., Moghimi, N., Rubinos, C.A., Nobleza, C.O., Sylaja, P.N., Toledano, M., Lattanzi, S., McCullough, L.D., Cruz-Flores, S., Torbey, M. and Azarpazhooh, M.R. (2020) Central Nervous System Manifestations Associated with COVID-19. Current Neurology and Neuroscience Reports, 20, Article No. 60. https://doi.org/10.1007/s11910-020-01079-7

[8] Asadi-Pooya, A.A. and Simani, L. (2020) Central Nervous System Manifestations of COVID-19: A Systematic Review. Journal of the Neurological Sciences, 413, 116832. https://doi.org/10.1016/j.jns.2020.116832

[9] Tan, Y.-K., Goh, C., Leow, A.S.T., Tambyah, P.A., Ang, A., Yap, E.-S., Tu, T.-M., Sharma, V.K., Yeo, L.L.L., Chan, B.P.L. and Tan, B.Y.Q. (2020) COVID-19 and Ischemic Stroke: A Systematic Review and Meta-Summary of the Literature. Journal of Thrombosis and Thrombolysis, 50, 587-595. https://doi.org/10.1007/s11239-020-02228-y

[10] Nannoni, S., de Groot, R., Bell, S., Markus, H.S. (2020) Stroke in COVID-19: A Systematic Review and Meta-Analysis. International Journal of Stroke, 16, 137-149. https://doi.org/10.1177/1747493020972922

[11] Morassi, M., Bagatto, D., Cobelli, M., D’Agostini, S., Gigli, G.L., Bnà, C. and Vogrig, A. (2020) Stroke in Patients with SARS-CoV-2 Infection: Case Series. Journal of Neurology, 267, 2185-2192. https://doi.org/10.1007/s00415-020-09885-2

[12] Escalard, S., Maïer, B., Redjem, H., Delvoye, F., Hébert, S., Smajda, S., Ciccio, G., Desilles, J.-P., Mazighi, M., Blanc, R. and Piotin, M. (2020) Treatment of Acute Ischemic Stroke due to Large Vessel Occlusion with COVID-19. Stroke, 51, 2540-2543. https://doi.org/10.1161/STROKEAHA.120.030574

[13] Atakla, H.G., Condé, K., Neishay, A., Barry, L.F., Bah, A.K., Konaté, M., Diallo, M.H., Mateen, F.J. and Cissé, F.A. (2020) Cerebrovascular Accidents Indicative of COVID-19 Infection: About 4 Observations in Guinea. Pan African Medical Journal, 35, Article No. 65. https://doi.org/10.11604/pamj.supp.2020.35.2.23751

[14] Escalard, S., Chalumeau, V., Escalard, C., Redjem, H., Delvoye, F., Hébert, S., Smajda, S., Ciccio, G., Desilles, J.-P., Mazighi, M., et al. (2020) Early Brain Imaging Shows Increased Severity of Acute Ischemic Strokes With Large Vessel Occlusion in COVID-19 Patients. Stroke, 51, 3366-3370. https://doi.org/10.1161/STROKEAHA.120.031011

[15] Altable, M. and de la Serna, J.M. (2020) Cerebrovascular Disease in COVID-19: Is 
There a Higher Risk of Stroke? Brain, Behavior, \& Immunity-Health, 6, Article No. 100092. https://doi.org/10.1016/j.bbih.2020.100092

[16] Zhou, F., Yu, T., Du, R., Fan, G., Liu, Y., Liu, Z., et al. (2020) Clinical Course and Risk Factors for Mortality of Adult Inpatients with COVID-19 in Wuhan, China: A Retrospective Cohort Study. Lancet, 395, 1054-1062. https://doi.org/10.1016/S0140-6736(20)30566-3

[17] Vogrig, A., Gigli, G.L., Bnà, C. and Morassi, M. (2021) Stroke in Patients with COVID-19: Clinical and Neuroimaging Characteristics. Neuroscience Letters, 743, Article No. 135564. https://doi.org/10.1016/j.neulet.2020.135564

[18] Kremer, S., Lersy, F., Anheim, M., Merdji, H., Schenck, M., Oesterlé, H., et al. (2020) Neurologic and Neuroimaging Findings in Patients with COVID-19: A Retrospective Multicenter Study. Neurology, 95, e1868-e1882.

https://doi.org/10.1212/WNL.0000000000010112

[19] Edén, A., Kanberg, N., Gostner, J., Fuchs, D., Hagberg, L., Andersson, L.-M., et al. (2021) CSF Biomarkers in Patients with COVID-19 and Neurologic Symptoms: A Case Series. Neurology, 96, e294-e300.

[20] Moriguchi, T., Harii, N., Goto, J., Harada, D., Sugawara, H., Takamino, J. et al. (2020) A first Case of Meningitis/Encephalitis Associated with SARSCoronavirus-2. International Journal of Infectious Diseases, 94, 55-58.

https://doi.org/10.1016/j.ijid.2020.03.062

[21] Al Saiegh, F., Ghosh, R., Leibold, A., Avery, M.B., Schmidt, R.F., Theofanis, T., Mouchtouris, N., Philipp, L., Peiper, S.C., Wang, Z.-X., Rincon, F., Tjoumakaris, S.I., Jabbour, P., Rosenwasser, R.H. and Gooch, M.R. (2020) Status of SARS-CoV-2 in Cerebrospinal Fluid of Patients with COVID-19 and Stroke. Journal of Neurology, Neurosurgery \& Psychiatry, 91, 846-848. https://doi.org/10.1136/jnnp-2020-323522

[22] World Health Organization (2021) Cameroon: WHO Coronavirus Disease (COVID-19) Dashboard [Internet]. https://covid19.who.int 